\title{
A novel mechanism of dasatinib-induced apoptosis in chronic myeloid leukemia; ceramide synthase and ceramide clearance genes
}

\author{
Emel B. Gencer • Ali U. Ural • Ferit Avcu • Yusuf Baran
}

Received: 8 October 2010 /Accepted: 8 March 2011 /Published online: 1 April 2011

(C) Springer-Verlag 2011

\begin{abstract}
Sphingolipids are bioeffector molecules that control various aspects of cell growth, proliferation, apoptosis, and drug resistance. Ceramides, the central molecule of sphingolipid metabolism, are inducer of apoptosis and inhibitors of proliferation. Sphingosine-1phosphate (S1P) and glucosyleceramide, converted from ceramides by sphingosine kinase-1 $(S K-1)$ and glucosyleceramide synthase $(G C S)$ enzymes, respectively, inhibit apoptosis and develop resistance to chemotherapeutic drugs. In this study, we examined the therapeutic potentials of bioactive sphingolipids in chronic myeloid leukemia (CML) alone and in combination with dasatinib in addition to investigate the roles of ceramide-metabolizing genes in dasatinib-induced apoptosis. Cytotoxic effects of dasatinib, C8:ceramide, PDMP, and $S K-1$ inhibitor were determined by XTT cell proliferation assay. Changes in caspase- 3 enzyme activity and mitochondrial membrane potential (MMP) were measured using caspase-3 colorimetric assay and JC-1 MMP detection kit. Expression levels of ceramide-metabolizing genes were examined by qRT-PCR. Application of ceramide analogs and inhibitors of ceramide clearance genes decreased cell proliferation and induced apoptosis. Targeting bioactive sphingolipids towards generation/accumulation of ceramides
\end{abstract}

E. B. Gencer · Y. Baran $(\bowtie)$

Department of Molecular Biology and Genetics, Faculty of Science, Izmir Institute of Technology, Gulbahce Campus, Urla, Izmir, Turkey

e-mail: yusufbaran@iyte.edu.tr

Y. Baran

e-mail: iytecancer@gmail.com

A. U. Ural · F. Avcu

Department of Hematology,

School of Medicine, Gülhane Medical School,

Etlik, Ankara, Turkey increased apoptotic effects of dasatinib, synergistically. It was shown for the first time that dasatinib induces apoptosis through downregulating expression levels of antiapoptotic $S K-1$ but not $G C S$, and upregulating expression levels of ceramide synthase (CerS) genes, especially CerS1, in K562 cells. On the other hand, dasatinib downregulates expression levels of both GCS and $S K-1$ and upregulate apoptotic CerS2, -5 and -6 genes in Meg-01 cells. Increasing endogenous ceramide levels and decreasing prosurvival lipids, S1P, and GC, can open the way of more effective treatment of CML.

Keywords Chronic myeloid leukemia - Dasatinib . Bioactive sphingolipids · Ceramides · Ceramide synthases · $\mathrm{BCR} / \mathrm{ABL}$

\section{Introduction}

Chronic myeloid leukemia is a hematopoetic stem cell disorder characterized by the presence of constitutively active breakpoint cluster region (BCR)/Abelson (ABL) oncoprotein [1]. BCR/ABL oncoprotein results from a reciprocal translocation of a section of human chromosome 9 that contains the ABL kinase domain and a specific BCR on chromosome $22[2,3]$. BCR/ABL oncoprotein regulates many signaling pathways involved in cell growth and proliferation, apoptosis, and differentiation [4]. It was shown by different studies that expression of BCR/ABL alone is enough to interpret chronic myeloid leukemia (CML) [5-7]. Development and application of imatinib that targets $\mathrm{BCR} / \mathrm{ABL}$ oncoprotein is an important milestone for the treatment of (CML). Imatinib binds to adenosine triphosphate (ATP)-binding site of $\mathrm{BCR} / \mathrm{ABL}$ and inhibits phosphorylation of $\mathrm{BCR} / \mathrm{ABL}$ targets that prevent leuke- 
mogenesis [8]. But, although very high hematological and cytogenetical responses were obtained in response to imatinib in the beginning, drug resistance was the major drawback in imatinib-based protocols [9].

Dasatinib, is a multikinase inhibitor that inhibits the activity of BCR/ABL and SRC kinases including SRC, LCK, YES, and FYN in addition to c-KIT and PDGFRalpha and beta [10]. It acts as a competitive inhibitor at the ATP-binding site of BCR/ABL, preventing tyrosine phosphorylation of the substrate molecule and downstream signaling, causing growth arrest and apoptosis [11]. Dasatinib demonstrated significant activity against the mutations on its binding site including the ones causing poor prognosis in imatinib treatment. Dasatinib is used for the treatment of BCR-ABL-positive CML, resistant or intolerant to imatinib patients while it is also approved for Philadelphia chromosome $(\mathrm{Ph})$ positive acute lymphoblastic leukemia patients [12]. Dasatinib also demonstrated antitumoral activities on solid tumors such as prostate, breast, lung or head, and neck cancers [13-16].

Bioactive sphingolipids ceramide, sphingosine 1-phophate (S1P), sphingosine, and glucosylceramide (GlcCer) are involved in initiation and progression of cancer. They regulate cell growth, cell proliferation, apoptosis, senescence, and drug resistance $[17,18]$. Ceramides are synthesized either de novo by ceramide synthase genes (CerS1-6) or by breakdown of sphingomyelin by sphingomyelinase enzyme [19]. Different length of ceramides were synthesized by different $C e r S$ genes [20]. While CerS1 is responsible for synthesis of C18-ceramide [21], $\mathrm{CerS} 2$ and CerS4 increase the levels of C24-ceramides and C22-ceramides, respectively [22, 23]. C14-ceramides and $\mathrm{C} 16$-ceramides were sythesised by CerS5 and CerS6 genes [24, 25]. Ceramides act as strong antitumoral molecules supressing cell growth and proliferation and inducing apoptosis and differentiation [26]. On the other hand, GlcCer and S1P molecules converted from ceramide by glucosylceramide synthase $(G C S)$ and sphingosine kinase-1 (SK-1) enzymes act as strong antiapoptotic molecules inducing cell growth and proliferation and inhibiting apoptosis and differentiation [27, 28]. Thus, the balance between ceramide/GlcCer or ceramide/S1P significantly affects the fate of the cell to die or to survive. It was also shown that intracellular concentrations of ceramides are increased in response to stress conditions. But in cancerous tissues and cells and in more agressive resistant cell expressions, levels of $G C S$ and $S K-1$ increases significantly [26-28].

In the present study, we examined the roles of ceramidemetabolizing genes in apoptosis in response to dasatinib in $\mathrm{Ph}$ positive (CML) cells. We also tried to increase apoptotic effects of dasatinib on CML cells by targeting bioactive sphingolipids.

\section{Materials and methods}

\section{Reagents}

Dasatinib was obtained from BMS, USA. A 10-mM stock solution was prepared with DMSO and stored at $-20^{\circ} \mathrm{C}$. C8:ceramide, N-(2-hydroxy-1-(4-morpholinylmethyl)-2phenylethyl)-decanamide, hydrochloride (PDMP), and SK-1 inhibitor were obtained from Cayman Chemicals, USA, dissolved in DMSO and stored at $-20^{\circ} \mathrm{C}$. The final concentration of DMSO did not exceed more than $0.1 \%$ in culture. Primers were obtained from Eurofins, Germany.

\section{Cell lines and culture conditions}

K562 and Meg-01 human CML cells were obtained from the German Collection of Microorganisms and Cell Cultures (Germany). The cells were cultured in RPMI-1640 growth medium containing $10 \%$ fetal bovine serum and $1 \%$ penicillin-streptomycin (Invitrogen, USA) at $37^{\circ} \mathrm{C}$ in $5 \% \mathrm{CO}_{2}$.

\section{Measurement of cell growth by XTT}

Antiproliferative effects of dasatinib, C8:ceramide, SK-1 inhibitor, and PDMP were determined by XTT cell proliferation assay as described previously [29]. Briefly, 96-well plates were seeded with $2 \times 10^{4}$ cells/well containing $200 \mu \mathrm{l}$ of the growth medium in the absence or presence of increasing concentrations of the agents. The cells were incubated at $37^{\circ} \mathrm{C}$ in $5 \% \mathrm{CO}_{2}$ for $72 \mathrm{~h}$. Then, they were treated with $40-\mu \mathrm{l}$ XTT for $4 \mathrm{~h}$ at $\mathrm{CO}_{2}$ incubator. After that, the plates were read at $490 \mathrm{~nm}$ by Elisa reader (Thermo Electron Corporation Multiskan Spectrum, Finland). Finally, IC50 values of dasatinib and C8:ceramide, and IC10 values of PDMP and SK-1 inhibitor were calculated from cell proliferation plots. We combined increasing concentrations of dasatinib with IC10 values of PDMP and $S K-1$ inhibitor since we have previously shown that IC10 values of these chemicals are enough to inhibit the enzyme activities and provide accumulation of ceramides in the cells [9]. In parallel experiments, we combined IC50 value of C8: ceramide with increasing concentrations of dasatinib since ceramide analogs trigger induction of generation of apoptotic ceramides at IC50 value [30]. The magic behind these experiments was to determine possible synergistic antiproliferative effects dasatinib on K562 and Meg-01 cells in which intracellular ceramide concentrations were increased.

Isobologram analysis for median dose effect

We used the CalcuSyn for Windows computer program (CalcuSyn software, Biosoft, Cambridge, UK) for isobologram analysis [31]. We studied the isobologram analysis of 
A
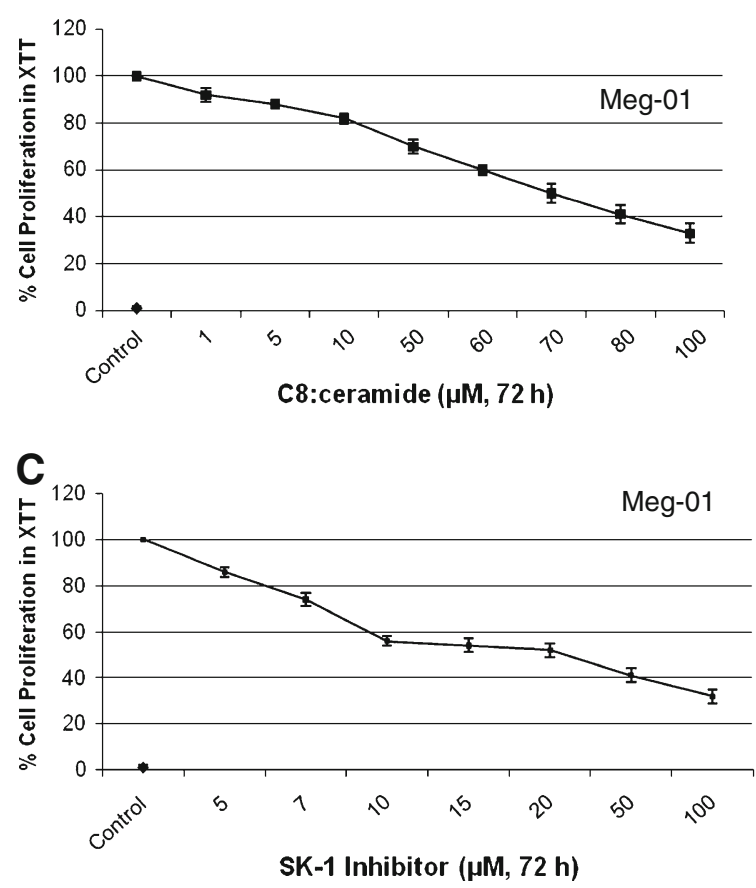

Fig. 1 Effects of ceramide analogs and inhibitors of ceramide clearence enzymes on proliferation of Meg-01 cells. Antiproliferative effects of C8: ceramide (a), PDMP (b), and $S K-1$ inhibitor (c) on CML cells were

dasatinib with C8:ceramide, PDMP, and $S K-1$ inhibitor using the computer software. Experimental data points represented by dots located below, on, or above the line, indicate synergism, additivity, and antagonism, respectively. The CI is an analysis of the combined effects of two drugs using a median effect plot analysis. A CI value $<1$ indicates a synergistic effect $(0.1-0.5$ strong synergism; $<0.1$ very strong synergism); a CI value of 1 indicates additive effect; and a CI value $>1$ an antagonistic effect (3.3-10 strong antagonism; $>10$ very strong antagonism).

Measurement of changes in caspase-3 enzyme activity

Changes in caspase-3 enzyme activity in response to applied anyone of these chemical agents were assessed by caspase-3 colorimetric assay kit (R\&D Systems, USA) as described previously [32]. The cells were treated with C8: ceramide, PDMP, or $S K-1$ inhibitor itself and in combination with dasatinib for $72 \mathrm{~h}$. Untreated cells were used as control group. The cells were collected by centrifugation at $1,000 \mathrm{rpm}$ for $10 \mathrm{~min}$, and treated with $100 \mu \mathrm{l}$ of cold lysis buffer (1X) to obtain cell lysate. After incubating the cell lysates on ice for $10 \mathrm{~min}$, they were centrifuged at $14,000 \mathrm{rpm}$ for $1 \mathrm{~min}$. Then, the supernatants were transferred to new microcentrifuge tubes. In order to measure caspase- 3 enzyme activity, reaction mixture including $20 \mu \mathrm{l}$ of assay buffer (5X), $25 \mu \mathrm{l}$ of sample, $50 \mu \mathrm{l}$



determined by the XTT cell proliferation test in a 72-h culture. The XTT assays were performed using triplicate samples in at least three independent experiments. The error bars represent the standard deviation

of sterilized water, and $5 \mu \mathrm{l}$ of caspase-3 colorimetric substrate was prepared in 96-well plates and incubated for $2 \mathrm{~h}$ at $37^{\circ} \mathrm{C}$. The samples were read under $405 \mathrm{~nm}$ wavelengths by Elisa reader (Thermo Electron Corporation Multiskan Spectrum, Finland). After measuring protein concentrations by Bradford assay, enzyme activity levels were normalized to protein concentrations.

Detection of the loss of mitochondrial membrane potential (MMP)

APO LOGIX JC-1 Assay Kit (Cell Technology, USA) was used to measure the changes in mitochondrial membrane potential in K562 and Meg-01 cells as described previously [32]. Shortly, the cells that had been induced to apoptosis were collected by centrifugation at $1,000 \mathrm{rpm}$ for $10 \mathrm{~min}$. Supernatants were removed, and $500 \mu \mathrm{l}$ of JC-1 dye (1\%) was added onto the pellets. After incubation of cells for $15 \mathrm{~min}$ at $37^{\circ} \mathrm{C}$ in $5 \% \mathrm{CO}_{2}$, they were centrifuged at $1,000 \mathrm{rpm}$ for $5 \mathrm{~min}$. Then, $2 \mathrm{ml}$ of assay buffer was added onto the pellets, and they were centrifuged for $5 \mathrm{~min}$ at $1,000 \mathrm{rpm}$. All the pellets were resuspended with $500 \mu \mathrm{l}$ assay buffer, and $150 \mu \mathrm{l}$ from each of them was added into black 96-well plate for a triplet measurement. The aggregate red form has absorption/emission maxima of 585/ $590 \mathrm{~nm}$, and the green monomeric form has absorption/ emission maxima of $510 / 527 \mathrm{~nm}$. The plate was read in 



Fig. 2 Effects of dasatinib, dasatinib/C8:ceramide/PDMP/SK-1 inhibitor combinations on proliferation of CML cells. Antiproliferative effects of dasatinib alone and dasatinib in combination with $\mathrm{C} 8$ : ceramide, PDMP, and SK-1 inhibitor on K562 (A) and Meg-01 (B) cells were determined by the XTT cell proliferation assay. The XTT assays were performed using triplicate samples in at least three independent experiments. The error bars represent the standard deviation. Statistical significance was determined using one-way analysis of variance, and $p<0.05$ was considered to be significant

these wavelengths by fluorescence Elisa reader (Thermo Varioskan Spectrum, Finland). Finally, green/red (510/585) values were calculated to determine the changes in MMP.

Total RNA isolation and quantitative reverse transcriptase$P C R$ The involvement of CerSl-6 and ceramide clearance genes (SK-1 and GCS) in dasatinib-induced apoptosis was investigated by examining the expression levels of these genes in response to dasatinib in K562 and Meg-01 cells. To achieve this aim, the cells were incubated in the absence and presence of increasing concentrations of dasatinib, and total cellular RNAs were isolated by using RNA Isolation Kit (Macherey-Nagel, USA). The amount and quality of RNAs were measured by Nanodrop Photospectrometer (NanoDrop 1000 THERMO, USA). The mRNAs from total RNA population were reverse transcribed into cDNA by using reverse transcriptase enzyme (Moroney Murine Leukemia Virus Reverse Transcriptase, Fermentas, USA). After $50 \mathrm{~min}$ incubation at $42^{\circ} \mathrm{C}$, the reactions were stopped at $95^{\circ} \mathrm{C}$ for $5 \mathrm{~min}$. The resulting total cDNA was used in qPCR to measure the mRNA levels of CerS1-6, SK-1, and GCS using
Roche LightCycler ${ }^{\circledR} 480$ Real-Time PCR System (Roche, USA). The mRNA levels of $\beta$ actin were used as internal positive control. The primer sequences were as follows:

CerS1-F (5'-CACTGCGCGCCTCTTTCG-3'); CerS1-R (5'-ATTGTGGTACCGGAAGGCG-3'); CerS2-F (5'-GCTGGAGATTCACATTTTAC-3',); CerS2-R (5'-GAAGACGATGAAGATGTTGT-3'); CerS4-F (5'-GTTTCAACGAGTGGTTTTG-3'); CerS4-R (5'-TGAATCTCTCAAAGGCAAG-3'); CerS5-F (5'-ATCTTCTTCGTGAGGCTG-3'); CerS5-R (5'-ATGTCCCAGAACCAAGGT-3'); CerS6-F (5'-ATCAGGAGAAGCCAAGCACG-3'); CerS6-R (5'-AGTAGTGAAGGTCAGTTGTG-3'); $S K-1$-F (5'-CCGACGAGGACTTTGTGCTAAT-3'); SK-1-R (5'-GCCTGTCCCCCCAAAGCATAAC-3'); GCS-F (5'-ATGACAGAAAAAGTA-3'); GCS-R (5'-GGACACCCCTGAGTG-3'); and $\beta$-actin-F (5'-CAGAGCAAGAGAGGCATCCT$\left.3^{\prime}\right)$; and -actin-R (5'-TTGAAGGTCTCAAACATGAT-3').

\section{Results}

C8:ceramide, PDMP, and $S K-1$ inhibitor decreased proliferation of CML cells in a dose-dependent manner

We have previously determined antiproliferative effects of C8:ceramide (IC50; $60 \mu \mathrm{M}$ ), PDMP (IC10; $20 \mu \mathrm{M}$ ), and $S K-1$ inhibitor (IC10; $7 \mu \mathrm{M})$ on K562 cells [33]. Increasing intracellular generation and accumulation of ceramides decreased proliferation of Meg-01 cells. IC50 value of C8:ceramide was calculated and found to be $70 \mu \mathrm{M}$ (Fig. 1a) and IC10 values of PDMP and $S K-1$ inhibitor were calculated as $50 \mu \mathrm{M}$ (Fig. 1b) and $5 \mu \mathrm{M}$ (Fig. 1c) for Meg-01 cells, respectively.

Dasatinib/C8:ceramide, /PDMP, and /SK-1 inhibitor inhibited proliferation of CML synergistically

The possible synergistic antiproliferative effects of combination of dasatinib with the ceramide analog and inhibitor of ceramide clearance enzymes were determined by XTT assay. IC50 concentration of C8:ceramide and IC10 concentrations of PDMP and $S K-1$ inhibitor were applied to K562 and Meg-01 cells in combination with increasing concentrations of dasatinib for $72 \mathrm{~h}$. IC50 concentrations of C8:ceramide were chosen based on its inhibitory effects on proliferation while IC10 values of PDMP and $S K-1$ inhibitor were preferred because at these concentrations they only inhibit enzyme activity but has no effect on 

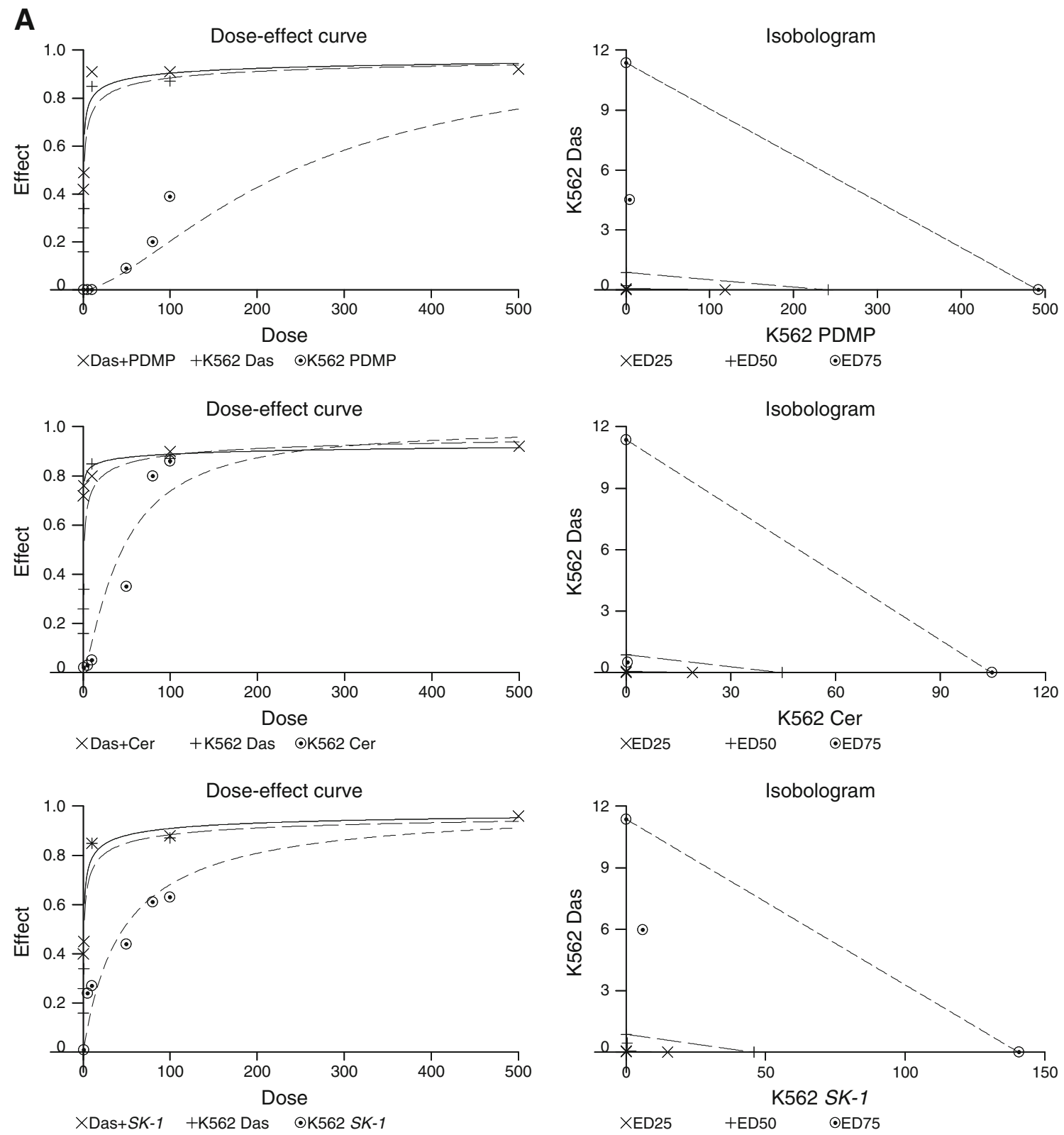

Fig. 3 Isobalogram analysis of combination of dasatinib with C8:ceramide, PDMP, and SK-1 inhibitor in K562 (a) and Meg-01 (b) cells

proliferation. CML cells were treated with different concentrations of dasatinib $(0.01$ to $100 \mathrm{nM})$ for $72 \mathrm{~h}$ to determine the effects on cell proliferation. IC50 of dasatinib was found as 4 and $55 \mathrm{nM}$ for K562 and Meg-01 cells, respectively (Fig. 2a, b).

There were $26 \%$ and $31 \%$ decreases in cell proliferation compared to untreated controls in response to 0.1 and $1 \mathrm{nM}$ dasatinib in K562 cells (Fig. 2a). But combinations of the same doses of dasatinib with IC50 concentration of C8: ceramide decreased proliferation of K562 cells by $72 \%$ and $76 \%$, with IC10 value of PDMP of $42 \%$ and $49 \%$, and with IC10 value of $S K-1$ inhibitor of $40 \%$ and $45 \%$ as compared to control, respectively (Fig. 2a).
Similar set of experiment was performed for Meg-01 cells. The results also demonstrated that there were synergistic antiproliferative effects of increasing concentrations of dasatinib (1-500 nM) with C8:ceramide, PDMP, and $S K-1$ inhibitor as compared to any agent alone and to untreated control group (Fig. 2b).

As shown in Fig. 3a, the CI values of dasatinib in combination with C8:ceramide, PDMP, and SK-1 inhibitor were $0.00160,0.26330$, and 0.26330 , respectively, in K562 cells. Combinations of dasatinib with $\mathrm{C} 8$ :ceramide, PDMP, and $S K-1$ inhibitor gave the CI values of $0.00258,0.00253$, and 0.23522 , respectively, in Meg-01 cells (Fig. 3b). A CI value $<1$ indicates a synergistic effect $(0.1-0.5$ strong 
B

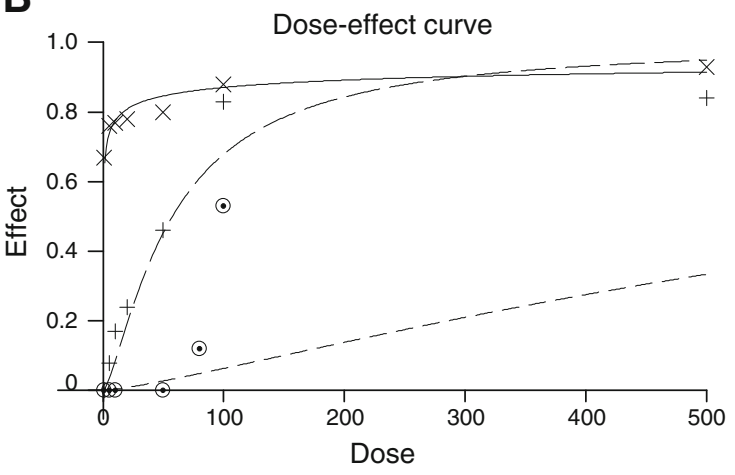

XDas+PDMP +MEG-01 Das $\odot M E G-01$ PDMP



$\times$ Das+Cer +MEG-01 Das $\odot M E G-01$ Cer



Fig. 3 (continued)

synergism; <0.1 very strong synergism). The results demonstrated that increasing intracellular concentrations of ceramide in dasatinib applied CML cells resulted in strong or very strong synergism.

The synergistic apoptotic effects of increased ceramide levels in combination with dasatinib

In order to determine the possible synergistic apoptotic effects of elevated ceramide levels in dasatinib-induced apoptosis, K562 and Meg-01 cells were pretreated with C8:ceramide, PDMP, and SK-1 inhibitor. The combinational effects of
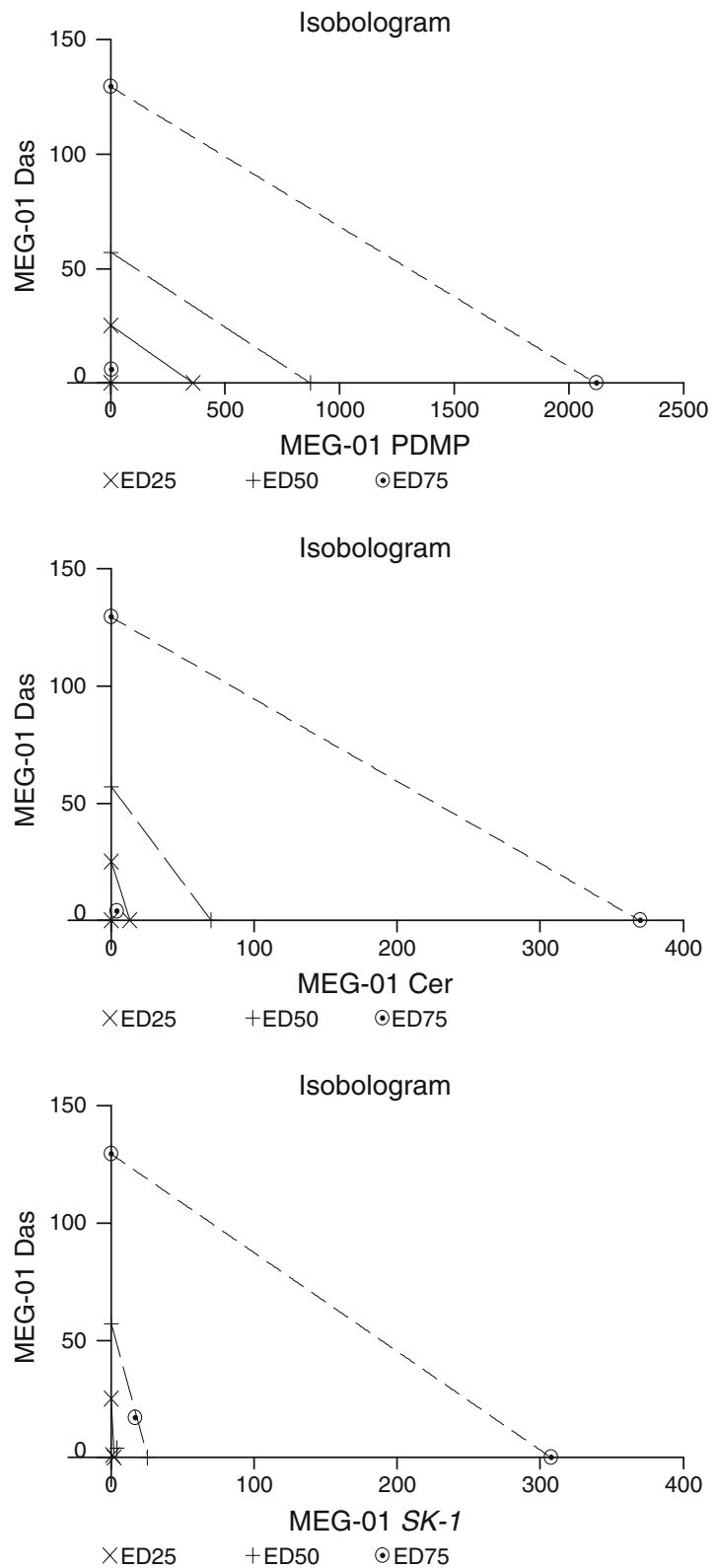

dasatinib with C8:ceramide, PDMP, and $S K-1$ inhibitor were examined by the loss of mitochondrial membrane potential (Fig. 4a, b) and increases in caspase-3 enzyme activity (Fig. 5a, b). The results showed that increasing intracellular concentrations of ceramides by any one of these agents or dasatinib application resulted in loss of MMP and increased caspase-3 enzyme activity in a dose-dependent manner compared to untreated controls to a certain extent. However, application of dasatinib in K562 and Meg-01 cells, pretreated with short-chain ceramides and inhibitors of ceramide clearance enzyme, caused significant loss of MMP and increases in caspase-3 enzyme activity in both K562 
Fig. 4 Percent changes in cytoplasmic/mitochondrial JC-1 in CML cells treated with combinations of dasatinib with $\mathrm{C} 8$ : ceramide, PDMP, and $S K-1$ inhibitor. The results are the means of three independent experiments. The error bars represent the standard deviations, and when not seen, they are smaller than the thickness of the lines on the graphs. Statistical significance was determined using two-way analysis of variance, and $p<0.05$ was considered to be significant

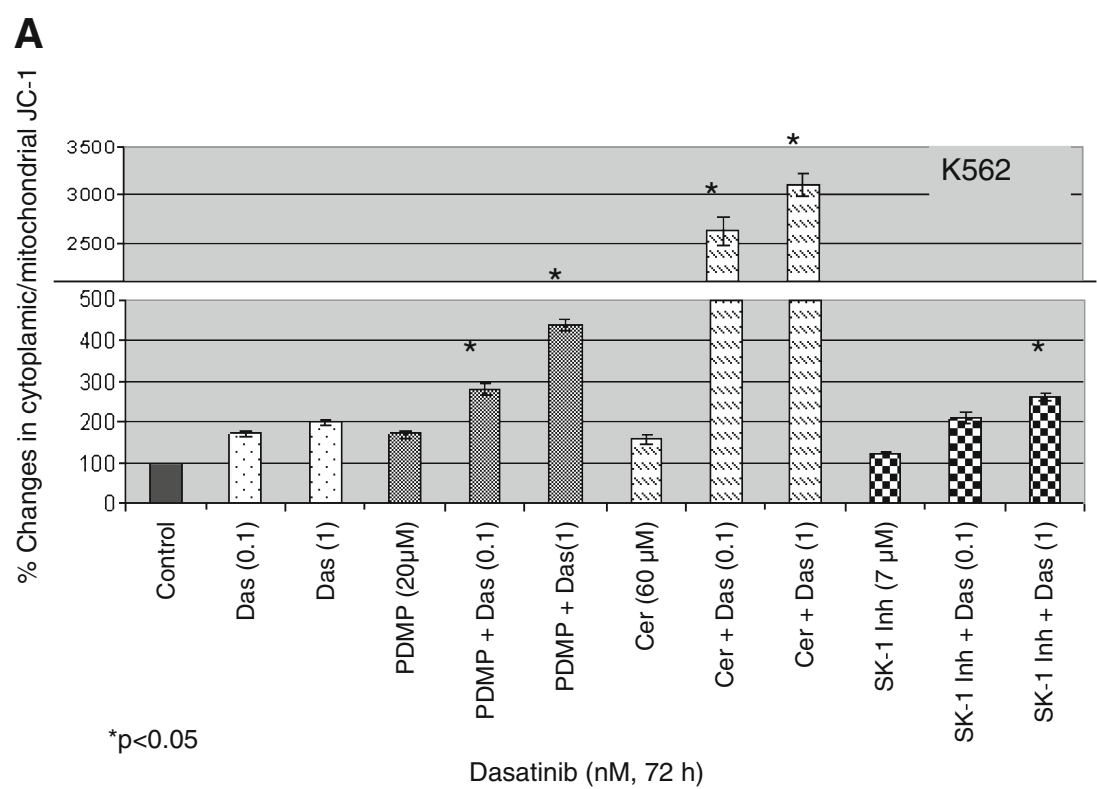

B

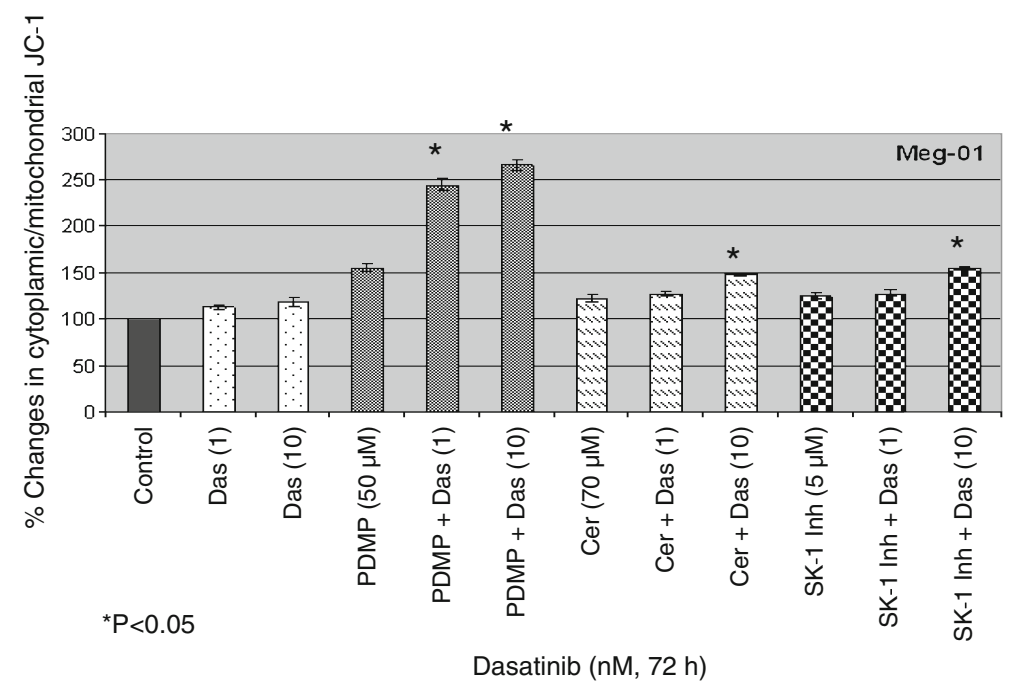

(Figs. 4a and 5a, respectively) and Meg-01 (Figs. 4b and 5b, respectively) cells. Apoptotic effects of low concentrations of dasatinib were increased by targeting ceramides. On the other hand, the most significant increases were observed in combination of dasatinib with $\mathrm{C} 8$ :ceramide as compared to others indicating that ceramide generation may be a more effective treatment way than inhibition of ceramide clearance.

The involvement of ceramide-metabolizing genes in dasatinib-induced apoptosis

In order to examine the role of ceramide generation and ceramide clearance genes in dasatinib-induced apoptosis, K562 and Meg-01 cells were exposed to increasing concentrations of dasatinib. Since Meg-01 cells are less sensitive to dasatinib, they were exposed to higher concentrations of dasatinib than K562 cells. qRT-PCR data showed that there were significant increases in expression levels of CerS1 (350\% and 530\%), CerS2 (250\% and 271\%), CerS4 (101\% and 101\%), CerS5 (160\% and 190\%), and CerS6 (124\% and $150 \%$ ) in K562 cells exposed to 0.1 and $1 \mathrm{nM}$ dasatinib, respectively (Fig. 6a), while expression levels of $S K-1$ decreased significantly (26\%). Interestingly, expression levels of GCS was increased in response to dasatinib. That may result from significant generation of ceramides.

On the other hand, $10 \mathrm{nM}$ dasatinib application resulted in $40 \%$ and $84 \%$ decreases in expression levels of antiapoptotic GCS and $S K-1$ genes in Meg-01 cells, respectively (Fig. 6b). There were 275\%, 129\%, and $168 \%$ increases in mRNA levels of apoptotic CerS2, Cers 5 , and CerS6 genes in response to $10 \mathrm{nM}$ dasatinib in Meg-01 cells while expression levels of CerS1 and CerS4 decreased 
Fig. 5 Percent changes in caspase-3 enzyme activity in response to coadministration of dasatinib with $\mathrm{C} 8$ :ceramide, PDMP, and $S K-1$ inhibitor. The results are the means of three independent experiments. The error bars represent the standard deviations, and when not seen, they are smaller than the thickness of the lines on the graphs. Statistical significance was determined using two-way analysis of variance, and $p<0.05$ was considered to be significant
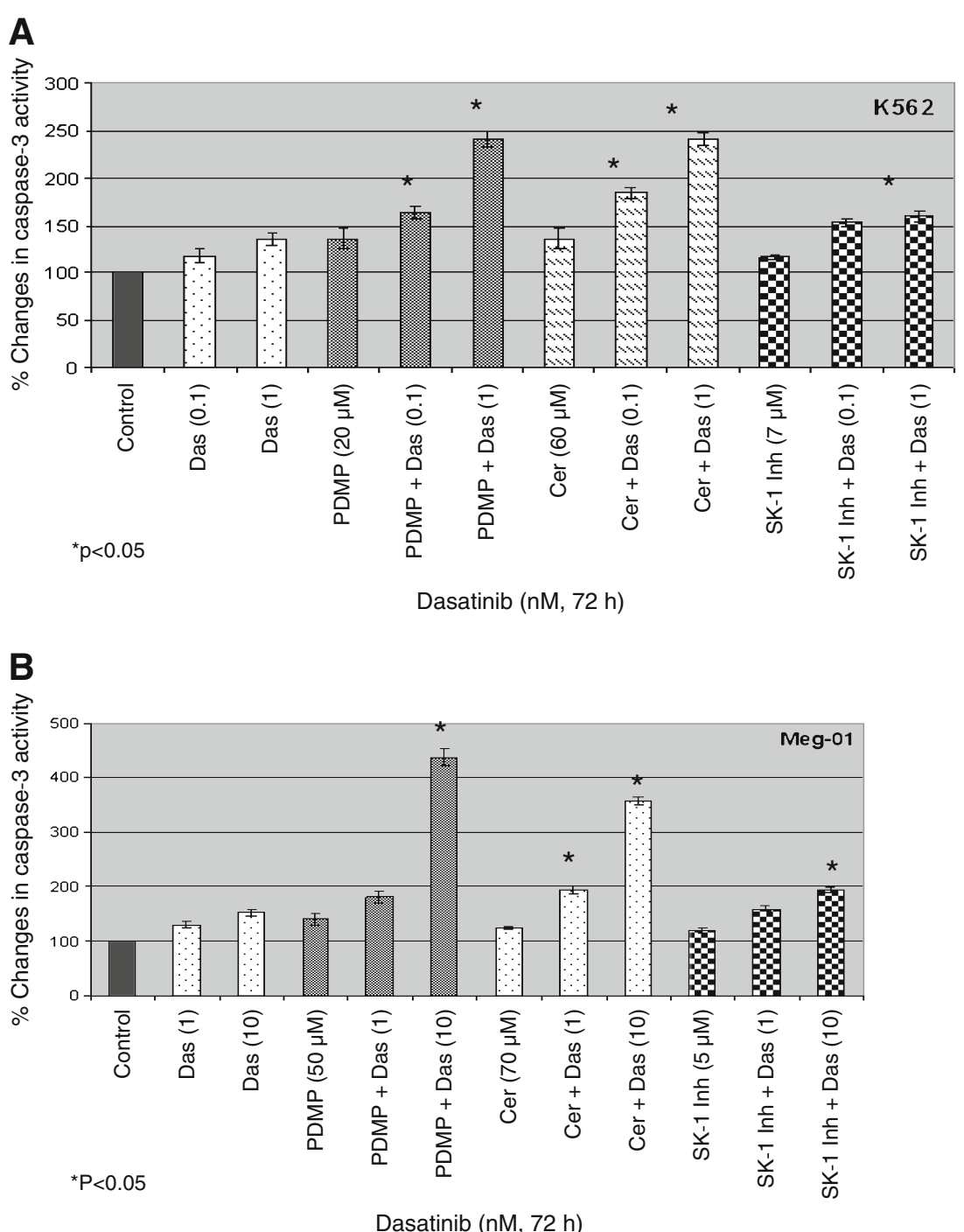

slightly as compared to untreated controls and normilized to beta-actin levels (Fig. 6b).

\section{Discussion}

Dasatinib is the second generation tyrosine kinase inhibitor that can bind both inactive and active forms of BCR/ABL [34]. Despite the fact that dasatinib is much more effective than imatinib for the treatment of CML, resistance to dasatinib is still the major drawback in CML treatment [35]. Therefore, increasing the sensitivity of CML cells to dasatinib can provide an important outcome.

Alterations in metabolism of bioactive sphingolipids are important regulators of tumor initiation, progression, and chemoresistance. The balance between proapoptotic and prosurvival signaling is affected by the ratio between ceramide and sphingosine-1-phosphate or glucosylceramide. Specific types of cancers can escape from cell death by converting ceramide to sphingosine-1-phosphate or to glucosyle ceramide by $S K-1$ and $G C S$ enzymes, respectively [36]. Therefore, targeting ceramide-metabolizing genes alone and in combination with anticancer agents may be an attractive treatment modality for various types of cancers. In the current study, we tried to increase apoptotic effects of dasatinib in combination with ceramide analogs and inhibitors of ceramide clearance enzymes.

It is very well-known that both exogenously applied C8ceramide, PDMP, and SK-1 inhibitors elevate endogenous ceramide concentrations in various types of cancers [9, 30]. In this study, we documented that inhibition of $G C S$ and $S K-1$ with specific chemical inhibitors and exogenous C8:ceramide application inhibited cell proliferation and induced apoptosis in a dose-dependent manner in both K562 and Meg-01 CML cells. We also treated K562 and Meg-01 cells with combination of dasatinib and PDMP or $S K-1$ inhibitor or C8:ceramide. All combinations induced apoptosis significantly as compared to any agent alone but the most 
Fig. 6 Expression levels of ceramide generation and ceramide clearence genes in response to dasatinib K562 and Meg-01 cells. 0.1 and $1 \mathrm{nM}$ dasatinib were applied to K562 cells while Meg-01 were exposed to $10 \mathrm{nM}$ dasatinib for $72 \mathrm{~h}$ and expression levels of ceramidemetabolizing genes were determined by qRT-PCR. Expression levels of beta actin were detected as internal positive controls

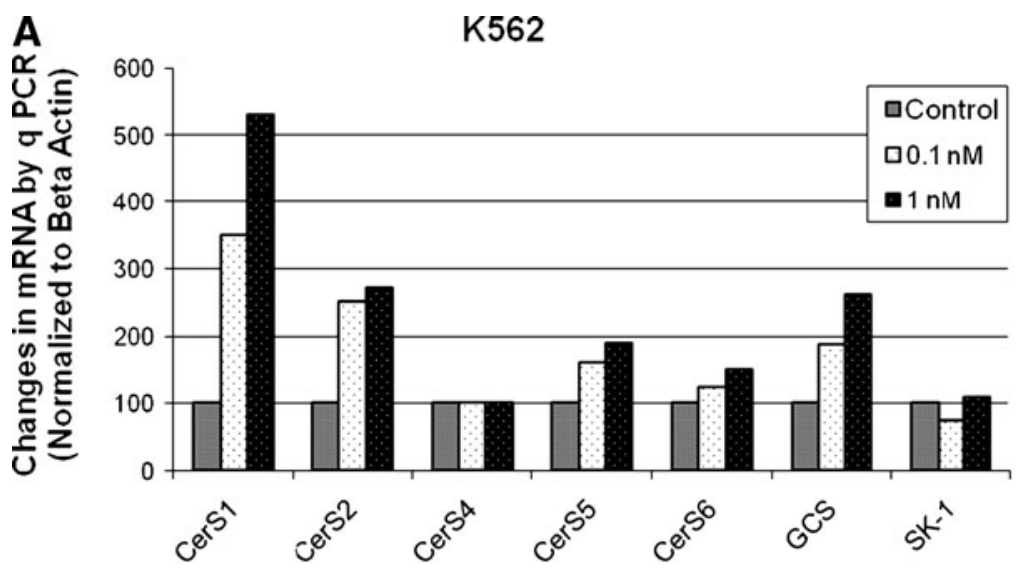

K562

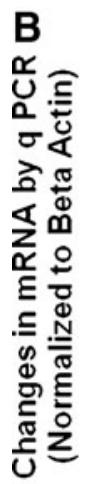

Meg-01

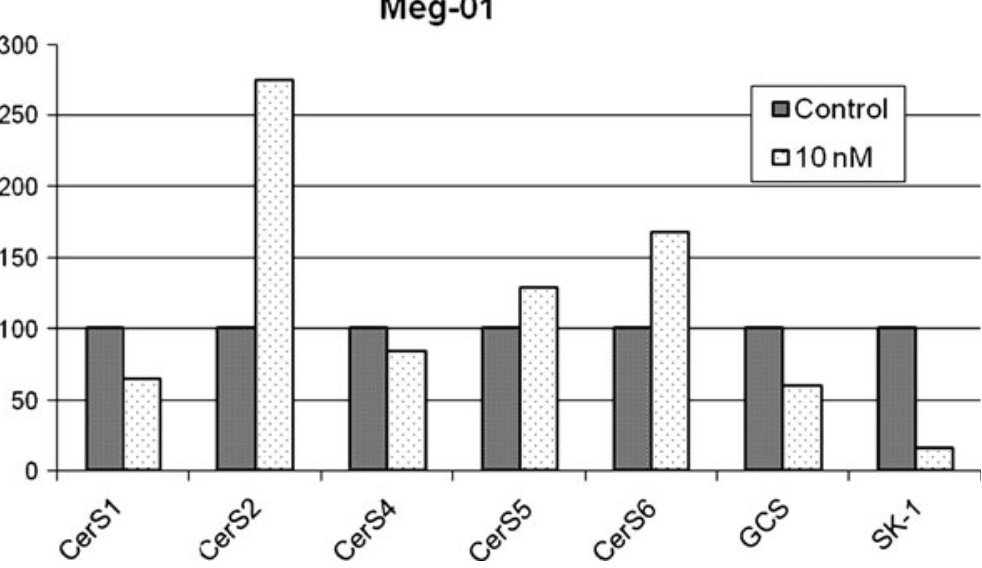

significant increase in apoptosis was observed in combination of dasatinib and C8:ceramide. It was also shown previously by our group and Senkal et al. that exogenous ceramide analog applications increased apoptotic effects of different anticancer agents in various types of cancers [37, 38].

Glucosyl ceramide synthase is the enzyme that transfers glucose to ceramide. Gouaze et al. have shown that inhibition of GCS increases sensitivity of resistant breast cancer cells to chemotherapy[39]. It was also shown that there is a direct relation between $G C S$ and drug resistance. They introduced GCS gene into sensitive MCF-7 breast cancer cells and observed an apparently increase in the GCS expression levels and as a result, the cells became adriamycin and exogeneous ceramides resistant [40].

Targeting sphingosine kinase-1 is a novel approach for the treatment of cancers. S1P is involved in tumor growth, proliferation, metastasis, and angiogenesis. Overexpression of $S K-1$ was observed in various types of tumors including lung, intestine, kidney, breast, and ovary tumor as compared to their normal counterpart tissues [41, 42]. $S K-1$ inhibitor, safingol, alone demonstrated antiproliferative effects on gastric, breast, neuroblastoma, lung, melanoma, prostate, colon, and pancreas cancers [43, 44]. Schwartz et al. demonstrated that safingol increased apoptotic effects of mitomycin-C synergistically in gastric cancer cells.

The antiproliferative and apoptotic effects of exogenous ceramides has been demonstrated in different human cancer cells [37, 38]. Struckhoff et al. have shown apoptotic effects of ceramide analogs on breast cancer cells while some other structural ceramide analogs also showed antiproliferative effects on adriamycin-resistant SKBr3 and MCF-7 human breast cancer cells [45, 46].

On the other hand, dasatinib has anticancer effects not only on CML but also on BCR/ABL negative tumors including chronic lymphoid leukemia, acute myeloid leukemia, prostate, lung, and non-small lung cancers [47-50]. In addition to inhibition of BCR/ABL, dasatinib can also target SRC family kinases, Lyn kinase, and EGFR [47-50]. In order to understand the mechanisms of dasatinib-induced apoptosis, we examined the expression patterns of ceramide-metabolizing genes in CML cells exposed to dasatinib. The qRT-PCR results revealed that there were significant increases in expression levels of CerS1, CerS2, CerS5, and CerS6 genes in response to dasatinib in K562 cells in a dose-dependent manner, while $S K-1$ is downregulated and slight increases were observed in expression pattern of $G C S$ as compared to untreated 
controls. On the other hand, there were upregulations of CerS2, CerS5, and CerS6 genes and downregulation in $S K 1$ and GCS in response to dasatinib in Meg-01 cells. The results of qRT-PCR analyses may explain the sensitivity of K562 cells to dasatinib as compared to Meg-01 cells. While IC50 value of dasatinib in K562 cells was $4 \mathrm{nM}$, it was $55 \mathrm{nM}$ for Meg-01 cells. While dasatinib downregulates expression levels of $S K-1$ and its application results in significant increases in expression levels of all $C e r S$ genes that result in increased generation and accumulation of apoptotic ceramides in K562 cells (Fig. 6a). However, in Meg-01 cells, since dasatinib application results in slight increases and even decreases in expression levels of ceramide-generating genes (Fig. 6b). On the other hand, there may be some other unknown mechanisms of dasatinib-induced apoptosis regulated differently in K562 and Meg-01 cells that results in differences in their sensitivity to dasatinib.

As a conclusion, in agreement with each other, our data demonstrated increasing intracellular concentrations of ceramides by targeting bioactive sphingolipids increased apoptotic effects of dasatinib synergistically. This approach being supported by clinical data may provide more effective treatment of CML patients.

Acknowledgments We thank Biotechnology and Bioengineering Center staff of Izmir Institute of Technology for their help and technical support. This study was supported by TUBITAK project number $107 \mathrm{~S} 317$ to Y. B. and by the Turkish Academy of Sciences Outstanding Young Investigator Programme.

Conflicts of interest statement We, the authors of the manuscript, do not have any conflicts of interest.

\section{References}

1. Druker BJ, Sawyers CL, Capdeville R, Ford JM, Baccarani M, Goldman JM (2001) Chronic myelogenous leukemia. Hematology Am Soc Hematol Educ Program 1:87-112

2. Shah NP (2007) Medical Management of CML. Hematology 371-375

3. Koca E, Haznedaroglu IC (2005) Imatinib mesylate and the management of chronic myeloid Leukemia (CML). Turk J Haematol 4:161-172

4. Deininger MWN, Goldman JM, Melo JV (2000) The molecular biology of chronic myeloid leukemia. Blood 96:3343-3356

5. Daley GQ, Van Etten RA, Baltimore D (1990) Induction of chronic myelogenous leukemia in mice by the P210bcr/abl gene of the Philadelphia chromosome. Science 247:824-830

6. Zhao RC, Jiang Y, Verfaillie CM (2001) A model of human p210 (bcr/ABL)-mediated chronic myelogenous leukemia by transduction of primary normal human CD34(+) cells with a BCR/ABLcontaining retroviral vector. Blood 97:2406-2412

7. Michor F, Iwasa Y, Nowak MA (2006) The age incidence of chronic myeloid leukemia can be explained by a one-mutation model. PNAS 103:14931-14934

8. Peng B, Hayes M, Resta D, Racine-Poon A, Druker BJ, Talpaz M, Sawyers CL, Rosamilia M, Ford J, Lloyd P, Capdeville R (2004)
Pharmacokinetics and pharmacodynamics of imatinib in a phase I trial with chronic myeloid leukemia patients. J Clin Oncol 22:935-942

9. Baran Y, Salas A, Senkal CE, Bielawski J, Gunduz U, Obeid LM, Ogretmen B (2007) Alterations of human longevity assurance gene 1 (LASS1)/sphingosine kinase-1-dependent ceramide generation and metabolism involve in the regulation of imatinibinduced apoptosis and resistance in K562 human chronic myeloid leukemia (CML) cells. J Biol Chem 282:10922-10934

10. Aguilera DG, Tsimberidou AM (2009) Dasatinib in chronic myeloid leukemia: a review. Ther Clin Risk Manag 5:281-289

11. Tokarski JS, Newitt JA, Chang CYJ, Cheng JD, Wittekind M, Kiefer SE, Kish K, Lee FYF, Borzillerri R, Lombardo LJ, Xie D, Zhang Y, Klei HE (2006) The structure of dasatinib (BMS354825) bound to activated ABL kinase domain elucidates its 1nhibitory activity against imatinib-resistant $\mathrm{ABL}$ mutants. Cancer Res 66:5790-5797

12. Lindauer M, Hochhaus A (2010) Dasatinib. Recent Results Cancer Res 184:83-102

13. Song L, Morris M, Bagui T, Lee FY, Jove R, Haura EB (2006) Dasatinib (BMS-354825) selectively induces apoptosis in lung cancer cells dependent on epidermal growth factor receptor signaling for survival. Cancer Res 66:5542-5548

14. Johnson FM, Saigal B, Talpaz M, Donato NJ (2005) Dasatinib (BMS-354825) tyrosine kinase inhibitor suppresses invasion and induces cell cycle arrest and apoptosis of head and neck squamous cell carcinoma and non-small cell lung cancer cells. Clin Cancer Res 11:6924-6932

15. Finn RS, Dering J, Ginther C, Wilson CA, Glaspy P, Tchekmedyian N, Slamon DJ (2007) Dasatinib, an orally active small molecule inhibitor of both the $s r c$ and $a b l$ kinases, selectively inhibits growth of basal-type/"triple-negative" breast cancer cell lines growing in vitro. Breast Cancer Res Treat 105:319-326

16. Nautiyal J, Majumder P, Patel BB, Lee FY, Majumdar APN (2009) Src inhibitor dasatinib inhibits growth of breast cancer cells by modulating EGFR signaling. Cancer Lett 283:143-151

17. Ogretmen B (2006) Sphingolipids in cancer: regulation of pathogenesis and therapy. FEBS Lett 580:5467-5476

18. Ogretmen B, Hannun YA (2004) Biologically active sphingolipids in cancer pathogenesis and treatment. Nature 4:604-616

19. Reynolds CP, Maurer BJ, Kolesnick RN (2004) Ceramide synthesis and metabolism as a target for cancer therapy. Cancer Lett 206:169-180

20. Pewzner-Jung Y, Ben-Dor S, Futerman AH (2006) When do lasses (longevity assurance genes) become $\operatorname{CerS}$ (ceramide synthases)? Insights into the regulation of ceramide synthesis. J Biol Chem 281:25001-25005

21. Venkataraman K, Riebeling C, Bodennec J, Riezman H, Allegood JC, Sullard MC, Merrill AH, Futerman AH (2002) Upstream of growth and differentiation factor 1 (uog1), a mammalian homolog of the yeast longevity assurance gene 1 (LAG1), regulates Nstearoyl-sphinganine (C18-(dihydro)ceramide) synthesis in a fumonisin B1-independent manner in mammalian cells. J Biol Chem 277:35642-35649

22. Mizutani Y, Kihara A, Igarashi Y (2005) Mammalian Lass6 and its related family members regulate synthesis of specific ceramides. Biochem J 390:263-271

23. Riebeling C, Allegood JC, Wang E, Merrill AH, Futerman AH (2003) Two mammalian longevity assurance gene (LAG1) family members, trh1 and trh4, regulate dihydroceramide synthesis using different fatty acyl-CoA donors. J Biol Chem 278:43452-43459

24. Weinmann A, Galle PR, Teufel A (2005) LASS6, an additional member of the longevity assurance gene family. Int J Mol Med 16:905-910

25. Xu Z, Zhou J, McCoy DM, Mallampalli RK (2005) LASS5 is the predominant ceramide synthase isoform involved in de novo 
sphingolipid synthesis in lung epithelia. J Lipid Res 46:12291238

26. Pettus BJ, Chalfant CE, Hannun YA (2002) Ceramide in apoptosis: an overview and current perspectives. Biochim Biophys Acta 1585:114-125

27. Lavie Y, Cao H, Bursten SL, Giuliano AE, Cabot MC (1996) Accumulation of glucosylceramides in multidrug-resistant cancer cells. J Biol Chem 271:19530-19536

28. Bonhoure E, Lauret A, Barnes DJ, Martin C, Malavaud B, Kohama T, Melo JV, Cuvillier O (2008) Sphingosine kinase-1 is a downstream regulator of imatinib-induced apoptosis in chronic myeloid leukemia cells. Leukemia 22:971-979

29. Piskin O, Ozcan MA, Ozsan GH, Ates H, Demirkan F, Alacacioglu I, Undar B (2007) Synergistic effect of imatinib mesylate and fludarabine combination on Philadelphia chromosome-positive chronic myeloid leukemia cell lines. Turk J Haematol 24:23-27

30. Senkal CE, Ponnusamy S, Rossi MJ, Bialewski J, Sinha D, Jiang JC, Jazwinski SM, Hannun YA, Ogretmen B (2007) Role of human longevity assurance gene 1 and C18-ceramide in chemotherapyinduced cell death in human head and neck squamous cell carcinomas. Mol Cancer Ther 6:712-722

31. Zhao L, Au JL, Wientjes MG (2010) Comparison of methods for evaluating drug-drug interaction. Front Biosci 2:241-249

32. Ekiz HA, Can G, Baran Y (2010) Nilotinib significantly induces apoptosis in imatinib resistant K562 cells, as effectively as in parental sensitive counterparts. Hematology 15:33-38

33. Kartal M, Saydam G, Sahin F, Baran Y (2009) Increasing intracellular generation or accumulation of ceramides increased cytotoxic effects of resveratrol in human K562 chronic myeloid leukemia cells. Haematologica 94:1241

34. Talpaz M, Shah NP, Kantarjian H, Donato N, Nicoll J, Paquette R, Cortes J, O'Brien S, Nicaise C, Bleickardt E, Blackwood-Chirchir MA, Iyer V, Chen T, Huang F, Decillis AP, Sawyers CL (2006) Dasatinib in imatinib-resistant Philadelphia chromosome-positive leukemias. N Engl J Med 354:2531-2541

35. Olivieri A, Manzione L (2007) Dasatinib: a new step in molecular target therapy. Ann Oncol 18:vi42-vi46

36. Zeidan YH, Hannun YA (2007) Translational aspects of sphingolipid metabolism. Trends Mol Med 13:327-336

37. Cakir Z, Saydam G, Sahin F, Baran Y (2011) The roles of bioactive sphingolipids in resveratrol-induced apoptosis in H160 acute myeloid leukemia cells. J Cancer Res Clin Oncol 137:279286

38. Senkal CE, Ponnusamy S, Rossi MJ, Sundararaj K, Szulc Z, Bielawski J, Bielawska A, Meyer M, Cobanoglu B, Koybasi S (2006) Potent antitumor activity of a novel cationic pyridiniumceramide alone or in combination with gemcitabine against human head and neck squamous cell carcinomas in vitro and in vivo. $\mathbf{J}$ Pharmacol Exp Ther 317:1188-1199
39. Gouazé V, Liu YY, Prickett CS, Yu JY, Giuliano AE, Cabot MC (2005) Glucosylceramide synthase blockade down-regulates Pglycoprotein and resensitizes multidrug-resistant breast cancer cells to anticancer drugs. Cancer Res 65:3861-3867

40. Liu YY, Han TY, Giuliano AE, Cabot MC (1999) Expression of glucosylceramide synthase, converting ceramide to glucosylceramide, confers adriamycin resistance in human breast cancer cells. J Biol Chem 274:1140-1146

41. Johnson KR, Johnson KY, Crellin HG, Ogretmen B, Boylan AM, Harley RA, Obeid LM (2005) Immunohistochemical distribution of sphingosine kinase 1 in normal and tumor lung tissue. J Histochem Cytochem 53:1159-1166

42. French KJ, Schrecengost RS, Lee BD, Zhuang Y, Smith SN, Eberly JL, Yun JK, Smith CD (2003) Discovery and evaluation of inhibitors of human sphingosine kinase. Cancer Res 63:5962-5969

43. Schwartz GK, Farsi K, Maslak P, Kelsen DP, Spriggs D (1997) Potentiation of apoptosis by flavopiridol in mitomycin-C-treated gastric and breast cancer cells. Clin Cancer Res 3:1467-1472

44. Maurer BJ, Melton L, Billups C, Cabot MC, Reynolds CP (2000) Synergistic cytotoxicity in solid tumor cell lines between N-(4hydroxyphenyl)retinamide and modulators of ceramide metabolism. J Natl Cancer Inst 92:1897-1909

45. Struckhoff AP, Bittman R, Burow ME, Clejan S, Elliott S, Hammond T, Tang Y, Beckman BS (2004) Novel ceramide analogs as potential chemotherapeutic agents in breast cancer. $\mathrm{J}$ Pharmacol Exp Ther 309:523-532

46. Crawford KW, Bittman R, Chun J, Byun HS, Bowen WD (2003) Novel ceramide analogs display selective cytotoxicity in drugresistant breast tumor cell lines compared to normal breast epithelial cells. Cell Mol Biol 49:1017-1023

47. Harr MW, Caimi PF, McColl KS, Zhong F, Patel SN, Barr PM, Distelhorst CW (2010) Inhibition of Lck enhances glucocorticoid sensitivity and apoptosis in lymphoid cell lines and in chronic lymphocytic leukemia. Cell Death Differ 17:1381-1391. doi:10.1038/cdd.2010.25

48. Lee YC, Huang CF, Murshed M, Chu K, Araujo JC, Ye X, Decrombrugghe B, Yu-Lee LY, Gallick GE, Lin SH (2010) Src family kinase/abl inhibitor dasatinib suppresses proliferation and enhances differentiation of osteoblasts. Oncogene 29:3196-3207. doi:10.1038/onc.2010.73

49. Li J, Rix U, Fang B, Bai Y, Edwards A, Colinge J, Bennett KL, Gao J, Song L, Eschrich S, Superti-Furga G, Koomen J, Haura EB (2010) A chemical and phosphoproteomic characterization of dasatinib action in lung cancer. Nature Chem Biol 6:291-299

50. Guerrouahen BS, Futami M, Vaklavas C, Kanerva J, Whichard ZL, Nwawka K, Blanchard EG, Lee FY, Robinson LJ, Arceci R, Kornblau SM, Wieder E, Cayre YE, Corey SJ (2010) Dasatinib inhibits the growth of molecularly heterogeneous myeloid leukemias. Clin Cancer Res 16:1149-1158 